\title{
Attitudes of Young Consumers in Chiang Mai, Thailand toward YouTube Online Video and Audio Advertising
}

\author{
Jui-Lung Chen ${ }^{1 *}$ and Chawakorn Panyaruang ${ }^{2}$
}

\begin{abstract}
With the increased use of the Internet, online audio and video are becoming more and more popular. The operating income of those websites providing online audio and video services is mainly from advertising. Therefore, not only advertisers need to care about the importance of the user' attitude toward advertising, but also the providers of online audio-visual service websites should understand it. This study focused on the attitude toward advertising of young consumers in Chiang Mai, Thailand, when they watch online audio-visual videos on YouTube, and explored their buying behaviors. The study found that entertainment, informativeness and credibility had a strong positive correlation with the attitude toward YouTube advertising, while irritability had a negative correlation. Based on the results of the analysis, this study provided future research directions for the academic community and the industry, as well as references for formulating business strategies and future development.
\end{abstract}

JEL classification numbers: M31, M37.

Keywords: Online audio-visual services, Attitude toward advertising, Buying behavior.

\footnotetext{
${ }^{1}$ Department of Business Administration, National Chin-Yi University of Technology, Taiwan, R.O.C

${ }^{2}$ Department of Business Administration, National Chin-Yi University of Technology, Taiwan, R.O.C
} 


\section{Introduction}

Advertising is one of the important tools for consumers to be interested in products or services. Over time, new advertisements will replace the old types of advertisements. Nowadays, almost every business is doing online advertising, and we see these advertisements on different mobile devices or computers almost every day. Therefore, social media has become an ideal channel to promote or use online advertising. The Internet and social media continue to grow with the number of users increasing rapidly, and they are also important for consumers in their daily lives. With the passage of time, there are more and more social media, such as Facebook, Twitter, Instagram and YouTube (Firat, 2019). Registered in 2005, YouTube is for sharing and exchanging video clips among users and has become the most popular audio-visual platform in the world. There are many different types of videos on YouTube including music, entertainment, news and knowledge. Internet users are allowed to view the videos, share video links on the site and exchange comments on the videos by posting comments (Bradshaw and Garrahan, 2008). In addition, the younger generation between the ages of 18 and 34 are considered the most frequent users, accounting for 2/3 of YouTube users, and they watch more YouTube videos than the programs on any cable channel (Perrin, 2015). According to statistics, YouTube is currently the world's second most used social platform, with more than 2 billion monthly logged-in users, second only to Facebook. YouTube is also the world's second most visited website, following its parent company Google. People watch more than 1 billion hours of videos on YouTube every day. Every year, more than $40 \%$ of advertisers place video ads on YouTube, and the ad cost for YouTube's top 100 advertisers increases by more than 60\% every year (Merchdope, 2019; Newberry, 2021).

The number of users has continued to grow since YouTube officially launched its service in Thailand in 2014. In particular, the recent COVID-19 pandemic has made many people choose to stay at home, so the home economy is booming, YouTube platform traffic has grown significantly, and YouTube is now an important channel for many brands to communicate with consumers (Pike and Yücel, 2020). Although TV is still the main media with a stable influence, social media such as YouTube continues to grow with increased advertising investment from many businesses (Adage, 2014; Bellman, Schweda and Varan, 2009; Clancey, 1994). Enterprises should no longer use traditional media alone to reach all customers. YouTube's advertising and traditional media advertising can complement each other to help companies reach more consumers and make effective use of advertising funds. The advertising using new media in combination with traditional media can cover more target customers. Moreover, compared with using traditional media only, using new media can save up to about 58\% (Sarttarasathit, 2020). Especially with the development of smartphones, social media is almost everywhere, which makes social media an important platform. Because of this, they are creating social media business for horizontal competition, including advertising on popular social media pages, and YouTube is one of them. YouTube's platform allows users to search and 
watch music, art, and entertainment videos. Therefore, the increase in YouTube usage makes YouTube a very important area for companies' exposure to the target audience (Firat, 2019)

Now every brand is trying to attract the attention of consumers in a media space that is too crowded for people to stand in, with each advertising channel that cannot be selected. This makes it more difficult on how to accurately measure marketing activities and find ways to increase advertising returns. Therefore, this involves the question of what marketers should do. YouTube is also one of the best advertising channels and there are many different types of advertising on YouTube. If advertising investors choose the right place for their brands, they can win the attention of customers and get the best return on investment. This raises the question of which types of advertising customers care most. So, the purpose of this study is to provide and study a comprehensive, integrated model of YouTube advertising and discuss the purchase behavior by targeting the attitudes of young consumers in Chiang Mai, Thailand, toward advertising when they are watching online video and audio videos on YouTube. Based on the analysis results, relevant suggestions on future research directions are made to the academic community and the industry for their reference of formulating business strategies and future development.

\section{Literature Review}

\subsection{Advertising}

Advertising means the announcements made in public places for open description or display of products to promote sales (Percy and Elliott, 2005). Advertising represents any paid form of non-personal display and the promotion of ideas, products, or services provided by designated sponsors (Kotler and Armstrong, 2017). Corporate advertising often tends to sell things, and is usually different from public services, political advertisements, or charities. Unlike personal sales, advertising is usually invisible communication. There are many advertisements that use actors or spokespersons, experts and celebrities as a means of personal promotion (Hackley, 2005). Advertising aims to make us interested in products or services by providing information or creating positive impressions (Percy and Elliott, 2005). Advertising is regarded as an integral part of the promotion mix and is a management tool defined by the nature of the promotion. Industry professionals usually think advertising as a powerful marketing tool and a means of persuasive communication with millions of customers (Hackley, 2005). The purpose of advertising is to convince the recipient or consumer to take immediate action or take further action in the future (Richards and Curran, 2002). Therefore, advertising is a promotional tool included in the marketing mix, in which the information about products and services is transmitted to the target audience through interactive mass media (such as television, print media, and radio) or via the Internet. Advertising is usually sponsored by sponsors with the purpose of informing, influencing, persuading, and attracting the target audience to choose products or services of a specific brand, and can increase the sponsor's sales and profits. Marketers need to 
understand the needs and wishes of customers and the market they are in. Advertising objectives are to complete a specific communication task with a specific target audience within a specific period. Advertising objectives can be classified into the objectives to inform, persuade or remind according to the main purpose (Kotler and Armstrong, 2017). One of the important tasks of a company is to carefully evaluate the relative effectiveness of each medium before investing in advertising (Smith, 1994). For many years, choosing media to convey advertising messages has been a fairly simple and clear process. Advertisers work with companies to design the most effective marketing methods for them (O'Guinn, Allen, Scheinbaum, Close and Semenik, 2019). The advertising options most suitable for the business of the company will depend on the target audience and the most cost-effective way to reach as many people as possible. To choose media, advertisers must decide the coverage and frequency required to achieve the advertising goals. The selected advertising options should also reflect the environment that suits the company's product or service. In addition, media planners must understand the coverage, frequency and impact of the main types of media (Kotler and Armstrong, 2017).

\subsection{Social Media}

Recently, there are many successful ways of online advertising, including display, email, Google AdWords, mobile and social. Traditional advertising has stabilized, while online advertising is growing rapidly. And this trend will not be out of date soon. Different from with the one-way nature of traditional advertising, online advertising allows users to interact and communicate in a smoother way. Of course, traditional advertising also has its advantages. For example, outdoor advertising can attract potential customers to the Internet, and then interact through display advertising, social media and e-mail. Offline and online advertising are inseparable, so both should be used in formulating marketing strategies (Dodson, 2016). Due to the popularity of online payment systems such as PayPal, more and more people are also shopping online. Companies are investing in Google AdWords for search engine optimization and natural search to connect with these multi-screen users in the most important places (Kritzinger and Weideman, 2013). In recent years, social media has begun to dominate the thinking of young consumers, and has brought about a huge shift in the marketing space in the past few decades, especially having a positive impact on buying behavior (Natarajan, Janarthanan, Senthil and Jeevananthan, 2014). Because of the large number of users, viewers, and followers of various social networking sites, retailers and manufacturers are using these advertising channels to reach current and potential customers. Compared with other types of advertising, social networks enable businesses to reach their target markets more directly (Gangadharbatla, 2008). As social networking sites allow users to create virtual reality of their real-world social relationships and promote the sharing of news and content, users' attention is usually focused on real-time, shared casual interactions between people, and the choice of media can vary according to needs 
and requirements (Jones, Malczyk and Beneke, 2011).

Social media marketing involves the use of Internet social media tools, such as YouTube, Facebook, Twitter, and Instagram to reach consumers innovatively. Social networks help promote companies and their activities. Active social networks try to attract more new customers or visitors. People are always more interested in following corporate social networks, rather than just visiting their websites. In social networks, people can interact with companies in a direct, very simple, and informal manner, and stronger two-way communication can be established, thereby enhancing mutual trust and strengthening brand image. Finally, after a lot of long-term work, corporate visibility can be increased. In order to achieve this goal, commercial social networks must be as active as their users, or even more active (Inkiriwang, Tumbuan and Tumewu, 2021). YouTube is a powerful social media and a content aggregator that hosts information and entertainment content. Users can upload and share their own videos, and upload videos placed by others (including companies). The reason YouTube is so effective for marketing is because its site can be used as an advertising medium or search platform. Marketers can publish videos of their products or brands which can be informative or entertaining. The site is particularly attractive to millennials and is a very sought-after market for many marketers so that YouTube has celebrities and video bloggers of its own and is now competing with previous advertising targeting radio and television. Many companies have now established their own YouTube channels, which allows them to have a brand-specific URL and fully customized content. Especially for teenagers, YouTube stars have a much greater influence on their purchasing decisions than TV or movie stars (Belch and Belch, 2017). According to the report of Pew Research Center, during the COVID-19 pandemic, YouTube has grown the most among all social media applications among U.S. users, and it is particularly popular among people aged 18 to 29 . In terms of attracting users, video is more powerful than any other form of media. YouTube platform ranks the first in the field of video sharing (Dodson, 2016; Rodriguez, 2021). There are many types of YouTube advertisements, including Skippable video ads, Nonskippable video ads, Bumper ads, Overlay ads, Video discovery ads, Outstream ads, and Masthead ads. Along with specifying a preliminary pattern for each format of the YouTube ad, each type of advertising channel has different advantages and disadvantages depending on whether the advertising investor chooses the type of product or service that suits its product or service, or chooses the channel that is the easiest for people to view so that customers can see its product (YouTube, 2021).

\subsection{Attitude toward Online Advertising}

The advertising value model proposed by Ducoffe (1995) is the theory most widely used to explain user perceptions and attitudes towards advertising. Based on the theory of media use and satisfaction, this model believes that media users are selectively exposed to the media according to their needs and motivation to seek satisfaction, to satisfy their utilitarian and/or hedonic needs. Ducoffe $(1995,1996)$ 
proved that entertainment, informativeness, and irritability affect people's attitudes towards online advertising. The content (informativeness) and form (entertainment) of advertising are important predictors of its value and are critical to the effectiveness of online advertising, and irritability has a negative impact on attitudes. Although some studies assume that the underlying structure of Internet advertising attitudes reflects one of the general attitudes toward advertising, Schlosser, Shavitt, and Kanfer (1999) believe that the unique characteristics of the Internet (which is mainly used as a medium for providing information) may also lead to a different underlying structure of attitudes towards Internet advertising. Their research considers that Internet advertising is more informative and more trustworthy. They found that not only the traditional advertising effect evaluation (i.e., information and entertainment value) is applicable to online advertising, and the effectiveness of advertising for making behavioral (purchase) decisions will also affect attitudes toward Internet advertising. Brackett and Car (2001) developed an integrated Web advertising attitude model which was modified from several early researchers. They proposed that attitudes toward online advertisements are the aggregation of weighted evaluations of perceived attributes and consequences of products. Based on this model, this study established a model of attitude toward online video advertising and its impact on consumer purchasing behavior.

\subsection{Entertainment}

Entertainment refers to anything provided to consumers to get satisfaction (satisfaction can be in any other form, not necessarily just enjoyment", but other responses, such as appreciation) (Zillmann and Vorderer, 2000; Vorderer, Klimmt and Ritterfeld, 2004; Oliver \& Bartsch, 2010). These responses can be found from external stimulus. For psychologists, entertainment is everything that people choose to consume in order to experience the positive effects belonging to the entertainment category: comedy, video games, sports, fiction, mystery, and other similar things (Oliver and Bartsch, 2010). Entertainment channels provide entertainment to interested users via a wide range of media (Eighmey and McCord, 1998). Previous research has shown that providing higher entertainment value encourages media users more frequently and is beneficial. Entertainment can also appear through advertising and convey the possibility of advertising and make users feel comfortable and enjoy the programs generated by advertisements (Lee and Choi, 2005).

Entertainment is based on emotional interaction and communication with the audience, which is something pleasant, whether it is laughter, tears or excitement. This kind of contribution is called participation and refers to the consumer's contribution to the product in terms of the psychological effect (Martin, 1998). Many studies believe that pleasant or likable advertisements have a positive impact on attitude toward brands. Therefore, this study proposed:

H1: Consumers' perception of the entertainment utility of YouTube advertising has a positive impact on the attitude toward YouTube advertising. 


\subsection{Informativeness}

Informativeness can be defined as the ability of advertisements to inform consumers of product alternatives, so that purchases can be made to generate the greatest possible satisfaction (Ducoffe, 1996). Clancy (1994) pointed out that media users could distinguish the advertising's ability to provide consumer information based on the fundamental reason of accepting the ad itself. Erdem, Swait, and Valenzuela (2006) found that consumers tend to show more signs of searching for product information, and obtain more information through unconditional exchange of interpersonal information. Many studies have shown the importance of the amount of information to the attitude toward online advertising. Therefore, social media provides suitable tools for this purpose because of the format, as it can display more product information (Lee and Choi, 2005).

Ducoffee $(1995,1996)$ and Brackett and Carr (2001) all found that the amount of information has a positive impact on online advertising, and Tsang, Ho, and Liang (2004) indicated that it has a positive impact on the value of mobile advertising. The research of Kim, Kim, and Park (2010) showed that the amount of information has a positive impact on both product participation and purchase intention. The research of Yang, Huang, Yang, and Yang (2017) on consumers' attitudes towards YouTube advertising detected that the amount of information has a positive effect on purchase attitudes. Therefore, the following was proposed:

H2: Consumers' perception of the informativeness utility of YouTube advertising has a positive impact on the attitude toward YouTube advertising.

\subsection{Irritation}

Ducoffe (1996) defined irritation as consumers' feelings in the face of advertisements when strategies that are annoying, offensive, insulting or overmanipulating are adopted for advertising, which has a great influence on consumers' attitudes toward advertising. Irritation can be described as the viewers' measurement criteria for messy and irritating content (Eighmey and McCord, 1998). For social media like YouTube, advertising-related irritation may be manifested as goal interruption and consumers' concerns about losing privacy (Corstjens and Umblijs, 2012). It was found in the research of Yang et al. (2017) that irritability has a negative impact on purchase attitude. So, the following was proposed:

H3: Consumers' perception of irritability has a negative impact on the attitude toward YouTube advertising.

\subsection{Credibility}

Credibility can be defined as the receiver's attitude toward the source of communication at a specific time (McCroskey, 1997). Credibility is one of the most important criteria for evaluating information quality (Bae and Lee, 2011). Ohanian (1990) pointed out that if the information source is trustworthy, attractive or from experts, it will induce more attitude and behavior compliance from consumers. Erdogan (1999) also confirmed that the high credibility of the information source 
will eventually lead to a positive impact on a favorable attitude toward the brand. Therefore, the following were proposed:

H4: Consumers' perception of the credibility of YouTube advertising has a positive impact on the attitude toward YouTube advertising.

H5: The amount of information, entertainment, irritation, and credibility has a positive impact on attitudes through YouTube advertising.

\subsection{Consumers Buying Behavior}

Social media is one of the main environments for reaching Gen Y consumers. Kemp, Borders, Anaza, and Johnston (2018) claimed that more than half of the people on the planet are regularly connected to virtual networks, and social networks have become an important part of marketing and sales strategies. The younger generation between the ages of 18 and 34, accounting for $2 / 3$ of YouTube users, watch YouTube videos more than any cable channel and are the most frequent users of this channel (Perrin, 2015). The consumer buying behavior related to advertising and its effectiveness has always been very important (Ajzen, Albarracin and Hornik, 2012). Consumers' behavior is actually affected by the emotional response after product advertising. However, sometimes advertisers exaggerate and over-promise the benefits and advantages of the product in a euphemistic way so that consumers are subconsciously affected. Psychologically speaking, it puts pressure on consumers through persuasiveness and makes them buy advertising products (Simons and Jones, 2017). Consumers make many buying decisions every day, and buying decisions are the focus of marketers' efforts. Most large companies study consumers' buying decisions in great detail to answer questions about what consumers buy, where they buy, how and how much they buy, when they buy, and why they buy (Kotler and Armstrong, 2017). Therefore, the following was put forward:

H6: Consumers' perception of the utility of attitude through YouTube advertising has a positive impact on consumer buying behavior.

\section{Methodology}

Figure 1 shows this study research model. The target population of this study was the population living in Chiang Mai, Thailand who were young users aged 18 to 29 using YouTube ads in 2021. The reason for choosing the 18-29 age group is because according to the survey of American social media users by Rodriguez (2021), Pew Research Center (Salvador Rodriguez, 2021), YouTube is the most popular social media among young people. According to the survey, YouTube's popularity among 18-29-year-olds is particularly high, and 95\% of them said they use the service. Therefore, the researchers chose this age group, which can also be extended in the following research, which is not specifically for young people, but extended to different age groups. The questionnaires were distributed online and 120 questionnaires were collected. This process took about three weeks (from April 7 to April 25, 2021). 


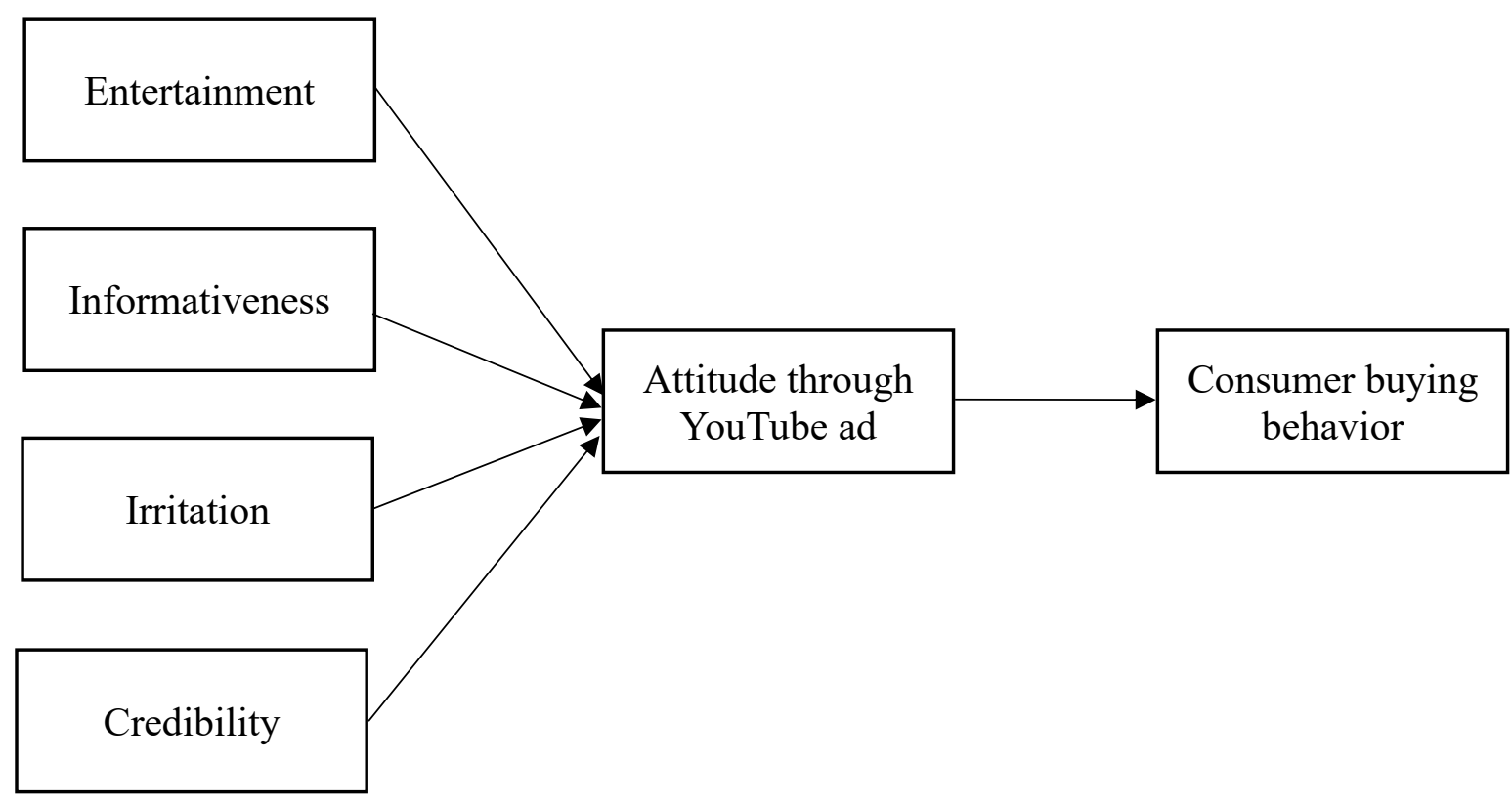

Figure 1: Research Model

The questionnaire survey method was employed by this study for the respondents who had known or watched YouTube videos on all channels (whether via telephone, computer or Internet TV). The convenient sampling method was adopted. The questionnaire was designed to measure with the Likert 5-point scale, which was divided into five levels from Strongly Agree to Strongly Disagree, with 5 points to 1 point meaning Strongly Agree, Agree, Neutral, Disagree, and Strongly Disagree, respectively. Each respondent gave each item the score of 1 to 5 as the evaluation value. Singh (2014) indicated the ability of reliability and validity can prove the transparency of research data and protect the bias of research data. Cronbach's $\alpha$ coefficient is a measure of the consistency of the questionnaire reliability of the reliability and reliability of the questionnaire of this study (Tavakol and Dennick, 2011). In the reliability analysis of each construct of this study, the Cronbach's $\alpha$ value is above 0.8 , and the statistical distribution data of each research factor analysis is quite good, showing that this study has good reliability and validity.

\section{Results}

\subsection{Impact of Advertising Entertainment on Attitude toward YouTube Advertising}

H1: Consumers' perception of the entertainment utility of YouTube advertising has a positive impact on the attitude toward YouTube advertising. A t-test was performed to determine whether entertainment in YouTube ads affects attitudes. It 
was found that this relationship had a significant impact because the average value was 4.0714, greater than the test value (median) and $t=8.806, p<0: 05$. There is not enough evidence to reject the hypothesis. Therefore, it can be concluded that consumers' perception of entertainment has an impact on attitude toward YouTube advertising, and $\mathrm{H} 1$ is supported.

\subsection{Impact of Advertising Informativeness on Attitude toward YouTube Advertising}

H2: Consumers' perception of the informativeness utility of YouTube advertising has a positive impact on the attitude toward YouTube advertising. A t-test was performed to determine whether the amount of information in YouTube advertising affects attitudes. It was found that this relationship had a significant impact because the average value was 4.0714 and greater than the test value (median) and $t=10.090$, $\mathrm{p}<0: 05$. There is not enough evidence to reject the hypothesis. Therefore, it can be concluded that consumers' perception of YouTube advertising has an impact on attitudes, which supports $\mathrm{H} 2$.

\subsection{Impact of Advertising Irritability on Attitude toward YouTube Advertising}

H3: Consumers' perception of irritability has a negative impact on the attitude toward YouTube advertising. A t-test was conducted to determine whether the irritability of YouTube ads will affect the attitude toward YouTube ads. It was found that the relationship had a negative impact, because the average value was 4.5000 and slightly larger than the test value (median value) and $t=16.684, p<0: 05$. There is not enough evidence to reject the hypothesis. Therefore, it can be concluded that consumers' perception of irritability of YouTube ads will affect their attitudes. H3 is supported.

\subsection{Impact of Advertising Credibility on Attitude toward YouTube Advertising}

H4: Consumers' perception of the credibility of YouTube advertising has a positive impact on the attitude toward YouTube advertising. A t-test was performed to determine whether the credibility of YouTube ads affects attitudes. It was found that this relationship had a significant impact, because the average value was 4.5714 , and greater than the test value (median), and $t=19.171, \mathrm{p}<0: 05$. There is not enough evidence to reject the hypothesis. Therefore, it can be concluded that consumers' perception of the credibility of YouTube advertising affects their attitudes, which supports $\mathrm{H} 4$.

\subsection{Amount of Information, Entertainment, Irritability, and Credibility Have a Positive Impact on Attitude through YouTube advertising}

H5: Consumers' perception of the utility of the amount of information, entertainment, irritation, and credibility has a positive impact on YouTube advertising, and thus positively affects their attitude toward YouTube. A t-test was 
performed to determine it, as shown in Table 4-6. It was found that this relationship had a significant impact, because the average value was 4.0952 , which is greater than the test value (median) and $t=9.139, \mathrm{p}<0: 05$. There is not enough evidence to reject the hypothesis. Therefore, it can be concluded that the consumer's perception of informativeness, entertainment, irritability, and credibility will have a positive impact on attitudes through YouTube ads that support H5.

\subsection{Impact of Attitude toward YouTube Advertising on Consumer Buying Behavior}

H6: Consumers' perception of the utility of attitude through YouTube advertising has a positive impact on consumer buying behavior. A t-test was conducted to determine whether attitudes affect consumer buying behavior through YouTube advertising. It was found that this relationship had a significant impact, because the average value was 4.0000 and greater than the test value (median), and $t=7.291$, $\mathrm{p}<0: 05$. There is not enough evidence to reject the hypothesis. Therefore, it can be concluded that consumers' perception of attitudes through YouTube advertising has an impact on consumer buying behavior, and $\mathrm{H} 6$ is supported.

\section{Discussion}

In addition to linking consumer perceptions with consumer buying behavior, the main goal of this study is to clarify the factors that affect attitudes towards YouTube advertising. In our study, the first five hypotheses involve communication, and we analyzed the advertising content in YouTube through the first five hypotheses. Finally, in the last hypothesis, we studied whether the attitudes toward YouTube advertising affect consumer buying behavior. The results showed that attitudes toward YouTube advertising significantly affected consumer buying behavior. This study shows that researchers have the opportunity to better understand YouTube channels' attitudes towards advertising factors. In addition, it also involves social media issues that may become the basis for performers. This study indicated that informativeness, entertaining, irritability, and all factors in advertising attitudes had an impact on consumer buying behavior. This study is valuable for companies that use YouTube advertising investment as part of their promotional strategies. Advertising customization is a positive driver for advertising attitudes. YouTube should display personalized video ads, not just text ads, because video marketing is as important as video production. Irritability is negatively related to the value of advertising, so marketers or advertisers should avoid any advertising that might be considered by consumers as irrelevant or irritable. YouTube should provide free services with the support of the company, and provide services to viewers as part of its advertising, which helps reduce irritability. 


\section{References}

[1] Adage, (2014). "YouTube effort boosts awareness, but what about ad sales?" available at: http://adage.com/article/digital/results-youtube-s-ads-vice-newsmakerstudios/294421/

[2] Ajzen, I., Albarracin, D. and Hornik, R. (Eds.). (2012). Prediction and change of health behavior: Applying the reasoned action approach. Psychology Press.

[3] Bae, S. and Lee, T. (2011). Product type and consumers' perception of online consumer reviews. Electronic Markets, 21(4), 255-266.

[4] Belch, E. and Belch, M. (2017). Advertising and Promotion: an integrated Marketing Communications Perspective, 11th edition. Irwin McGraw-Hill: Boston.

[5] Bellman, S., Schweda, A. and Varan, D. (2010) The Residual Impact of Avoided Television Advertising. Journal of Advertising, 39, 67-81.

[6] Bradshaw T. and Garrahan M. 2008. Rival forecast to catch YouTube, Financial Times, Available from: http://us.ft.com/ftgateway/superpage.ft?news_id=fto1116200 81851222523

[7] Brackett, L. K. and Carr, B. N. (2001). Cyberspace Advertising vs. Other Media: Consumer vs. Mature Student Attitudes. Journal of Advertising Research, 41(5), 23 - 32.

[8] Clancey, M. (1994). Winne-rof-arfs-1994 Lysaker, Richard, L. Prize for outstanding research on media - The television audience examined. Journal of Advertising Research, 34(4), 38-49.

[9] Corstjens, M. and Umblijs, A. (2012). The power of evil. Journal of Advertising Research, 52.4, 433-449.

[10] Dodson, I. (2016). The Art of Digital Marketing: The Definitive Guide to Creating Strategic, Targeted and Measurable Online Campaigns. Wiley.

[11] Ducoffe, R. H. (1995). How Consumers Assess the Value of Advertising. Journal of Current Issues and Research in Advertising. 17(1), 1-18.

[12] Ducoffe, R. H. (1996). Advertising Value and Advertising on the Web. Journal of Advertising Research, 36(5), 21-35.

[13] Eighmey, J. and McCord, L. (1998). "Adding Value in the Information Age: Uses and Gratifications of Sites on the World Wide Web," Journal of Business Research, Elsevier, vol. 41(3), pages 187-194.

[14] Erdem, T., Swait, J. and Valenzuela, A. (2006). Brands as signals: a crosscountry validation study. Journal of Marketing, 70(1), 34-49.

[15] Erdogan, Z. B. (1999). Celebrity endorsement: A literature review. Journal of Marketing Management, 15(3), 291-314.

[16] Firat, D. (2019). YouTube advertising value and its effects on purchase intention. Journal of Global Business Insights, 4(2), 141-155.

[17] Gangadharbatla, H. (2008). Facebook Me: Collective Self-Esteem, Need to Belong, and Internet Self-Efficacy as Predictors of the iGeneration's Attitudes toward Social Networking Sites. Journal of Interactive Advertising, 8, 5-15.

[18] Hackley, C. (2005). Advertising and Promotion. SAGE Publications Inc. 
[19] Inkiriwang, N., Tumbuan, W. and Tumewu, F. (2021). Analyzing of Youtube's Advertising On Consumer Buying Interest (Study Case: Students Of Sam Ratulangi University), Jurnal EMBA, Vol.9 No.1 Januari 2021, Hal. 236-244.

[20] Jones, A., Malczyk, A. and Beneke, J. (2011). Internet Marketing: a highly practical guide to every aspect of internet marketing. Textbook. University of Cape Town.

[21] Kemp, E. A., Borders, A. L., Anaza, N. A. and Johnston, W. J. (2018). The heart in organizational buying: marketers understanding of emotions and decision-making of buyers, Journal of Business and Industrial Marketing, 33(1), 19-28.

[22] Kim, J. U., Kim, W. J. and Park, S. C. (2010). Consumer perception on web advertisements and motivation factors to purchase in the online shopping. Computers in Human Behavior, 26, 1208-1222.

[23] Kotler P. and Armstrong G. (2017). Principle of marketing 17th Ed, Pearson Education Inc. Prentice Hall.

[24] Kritzinger, W. and Weideman, M. (2013). Search Engine Optimization and Pay-per-Click Marketing, Strategies Journal of Organizational Computing and Electronic Commerce, 23(3), 273-286.

[25] Lee, W. N. and Choi, S. M. (2005). The role of horizontal and vertical individualism and collectivism in online consumers' responses toward persuasive communication on the Web. Journal of Computer-Mediated Communication, 11(1), 317-336.

[26] Martin, C L. (1998). "Relationship marketing: a high-involvement product attribute approach." Journal of Product and Brand Management 7 (1): 6-26.

[27] McCroskey, J. C. (1997). An introduction to rhetorical communication (7th ed). Boston, MA: Allyn and Bacon.

[28] Merchdope (2019). "37 Mind Blowing YouTube Facts, Figures and Statistics - 2019." Merchdope.com, An Elite Cafemedia, 29 September 2019, https://merchdope.com/youtube-stats/

[29] Natarajan, T., Janarthanan, B., Senthil, A. and Jeevananthan, M. (2014). "Perception of Indian consumers towards social media advertisements in Facebook, LinkedIn, YouTube and Twitter", International Journal of Internet Marketing and Advertising, Vol. 8, No. 4, pp.264-284.

[30] Newberry, (2021). 25 YouTube Statistics that May Surprise You: 2021 Edition https://blog.hootsuite.com/youtube-stats-marketers/.

[31] O'Guinn, T. C, Allen, C., Semenik, R. and Scheinbaum, A. C. (2019). Advertising and Integrated Brand Promotion, 8th Ed. Mason OH: Cengage.

[32] Ohanian, R. (1990). Construction and validation of a scale to measure celebrity endorsers' perceived expertise, trustworthiness, and attractiveness. Journal of Advertising, 19(3), 39-52

[33] Oliver, M. and Bartsch, A. 2010. "Appreciation as audience response: exploring entertainment gratification beyond hedonism." Human Communication Research 36 (1): 53-81. 
[34] Percy, L. and Elliott, R. (2005). Strategic Advertising Management (2nd ed.). Oxford University Press.

[35] Perrin, A. (2015). Social Media Usage 2005-2015. Pew Internet \& American Life Project, Washington DC.

[36] Pike, S. and Yücel, Y. (2020). What are people in Thailand watching online. Retrievedfrom:https://www.thinkwithgoogle.com/intl/enapac/country/thailand/there-something-everyone-what-are-people-thailandwatching-online

[37] Richards, J. I. and Curran, C. M. (2002). Oracles on "advertising": Searching for a definition. Journal of Advertising, 31, 63-78.

[38] Rodriguez, S. (2021). YouTube is social media's big winner during the pandemic. Retrieved from: https://www.cnbc.com/2021/04/07/youtube-issocial-medias-big-winner-during-the-pandemic.html.

[39] Sarttarasathit, Y. (2020). 4 ways to advertise on YouTube for better results. Retrieved from:https://www.thinkwithgoogle.com/intl/th-th/marketingstrategies/video/4-innovative-ways-brands-are-driving-result-with-youtube/

[40] Schlosser, A., Shavitt, S., and Kanfer, A. (1999). Survey of Internet users' attitudes toward Internet advertising. Journal of Interactive Marketing, vol. 13, pp. 34-54.

[41] Singh. A. S. (2014). Conducting case study research in non-profit organizations. Qualitative Marketing Research: An International Journal. 17, $77-84$.

[42] Simons, H. W. and Jones, J. G. (2017). Persuasion in society. Routledge.

[43] Smith, J. (1994). The advertising KIT: A Complete Guide for Small Business. Lexington Books: New York.

[44] Tavakol, M. and Dennick, R. (2011). Making sense of Cronbach's alpha. International Journal of Medical Education, 2, 53-55.

[45] Tsang, M. M., Ho, S. C. and Liang, T. P. (2004). Consumer attitudes toward mobile advertising: An empirical study. International Journal of Electronic Commerce, 8(3), 65-78.

[46] Vorderer, P., Klimmt, C. and Ritterfeld, U. (2004). Enjoyment: at the heart of media entertainment." Communication Theory 14 (4): 388-408.

[47] Yang, K. C., Huang, C. H., Yang, C., and Yang, S. Y. (2017). Consumer attitudes toward online video advertisement: YouTube as a platform. Kybernetes, 46(5), 841-853.

[48] YouTube. (2021). YouTube advertising formats. Retrieved from: https://support.google.com/youtube/answer/2467968?hl=en

[49] Zillmann, D. and Vorderer, P. (Eds.). (2000). Media entertainment: The psychology of its appeal. Mahwah, NJ: Lawrence Erlbaum Associates. 